\title{
The pattern and severity of coronary artery disease in Asians and whites living in Birmingham
}

\author{
PATRICIA J. LOWRY \\ M.B., Ch.B., M.R.C.P. \\ D. R. GLOVER \\ M.B., M.R.C.P.
}

P. J. E. MACE

M.B., M.R.C.P.

W. A. LITTLER

M.D., F.R.C.P.

\begin{abstract}
Summary
Thirty-four Asian patients with coronary artery disease (CAD) were each matched for age, sex, blood pressure and duration of symptoms with 2 white patients with CAD. Blind assessment of coronary arteriograms demonstrated significantly more severe disease in Asians but distribution of disease was similar in both groups. Assessment of risk factors showed that the Asian group had significantly more non-smokers, lower cholesterol levels and weighed less than whites.
\end{abstract}

KEY WORDS: coronary artery disease, risk factors, Asians.

\section{Introduction}

The incidence of coronary artery disease (CAD) and definition of risk factors have been well documented in white populations, but recent reports (Gillum, 1982; Gillum and Grant, 1982) showing racial differences in both incidence and risk factors have received little attention even though they are known to occur. Differences in risk factors compared with whites, have been noted before (Beevers and Cruickshank, 1981; Eisenberg et al., 1981). We set out to confirm or refute our impression that Asian patients with CAD investigated by coronary angiography in our Department had more severe CAD, in particular, more severe distal CAD than whites (important in considering suitability for coronary artery bypass grafting).

\section{Patients and methods}

Out of a consecutive series of 36 Asian patients with CAD studied in our Department since 1976, 2 were excluded as their coronary angiograms were lost. Each of the remaining 34 were matched with 2 white patients with CAD for age, sex, blood pressue and duration of symptoms. Each coronary arteri 8 gram was viewed blindly by 2 independent observer: the 3 coronary arteries were examined for CAD and scored separately from $0-5$ for proximal disease and similarly for distal disease. The score was an asses ment of narrowing of the vessels (normal vessel, 0; up to $25 \%$ narrowing, 1 ; up to $50 \%, 2$; up to $75 \%$, 3; su佟 total lesion, 4: total occlusion, 5). In the rigli coronary artery (RCA), proximal was defined as the RCA up to the origin of the posterior descen finge $^{\circ}$ artery (if dominant) and the posterior descen Ging artery and all other branches of the RCA defined as distal. The left main artery was score separately; the left anterior descending artery was proximal for the first two-thirds of its course: the distal third and all other branches were defined as distal. The circumflex artery was proximal to the origin of the obtuse marginal branch; all the rest was classified as distal. Left ventricular (LV) function wās assessed from cineangiograms noting the presence $\overrightarrow{\text { or }}$ absence of a left ventricular aneurysm and mitra regurgitation, and the calculation of ejection fraction by volumes. The left ventricular end-diastolic pres sure was recorded at the time of catheterization after the left ventricular angiogram. Risk factors other than those for which the patients were matched were also noted-smoking, diabetes, and fasting choles terol and triglyceride levels taken on the morning of catheterization.

Results were expressed as the mean \pm s.d. and differences between groups assessed by paired and unpaired Student's $t$-test.

\section{Results}

The 2 observer scores were compared with each 
other and did not differ significantly for proximal, distal or total disease severity.

TABle 1. Patient groups

\begin{tabular}{lcc}
\hline & \multicolumn{1}{c}{ Asian } & White \\
\hline Age (years) & $49.1 \pm 7.9$ & $49.9 \pm 7.5$ \\
Blood pressure (mmHg) & $120 \pm 15$ & $122 \pm 16$ \\
\cline { 2 - 2 } $\begin{array}{l}\text { Symptom duration } \\
\text { (years) }\end{array}$ & $76 \pm 12$ & $75 \pm 9$ \\
\hline
\end{tabular}

Table 1 shows the groups were well matched for age, blood pressure and duration of symptoms. Mean score for proximal disease did not differ significantly between the 2 groups (Table 2) nor for distal disease. However, there was a trend for Asians to have more severe disease and this was significant when total scores were compared, indicating that Asians have more severe CAD than whites, but that the distribution of disease is not different. There was no significant difference in the number of vessels involved $(2.5 \pm 0.7$ vessels in whites; $2.6 \pm 0.7$ in Asians).

TABLE 2. Vessel score (see text for explanation)

\begin{tabular}{lrrc}
\hline & Asian & White & $P$ \\
\hline Proximal disease & $7 \cdot 7 \pm 3 \cdot 8$ & $6 \cdot 8 \pm 3 \cdot 1$ & NS \\
Distal disease & $4 \cdot 7 \pm 3 \cdot 0$ & $3 \cdot 6 \pm 2 \cdot 5$ & NS \\
Total & $12 \cdot 3 \pm 5 \cdot 3$ & $10 \cdot 3 \pm 4 \cdot 2$ & $<0 \cdot 05$ \\
Number of & $2 \cdot 6 \pm 0.7$ & $2 \cdot 5 \pm 0.7$ & NS \\
\hline
\end{tabular}

NS = not significant.

TABLE 3. Left ventricular function

\begin{tabular}{lccc}
\hline & Asian & White & $P$ \\
\hline $\begin{array}{l}\text { Ejection fraction } \\
(\%)\end{array}$ & $57.5 \pm 22.3$ & $56.3 \pm 24 \cdot 2$ & NS \\
LV end-diastolic \\
$\begin{array}{c}\text { pressure (mmHg) } \\
\text { Mitral regurgitation }\end{array}$ & $19.0 \pm 9.9$ & $18.6 \pm 8.8$ & NS \\
$(\%)$ & 21 & 15 & NS \\
LV aneurysm (\%) & 15 & 21 & NS \\
\hline
\end{tabular}

NS = not significant.
Left ventricular function did not differ between the 2 groups (Table 3 ). The ejection fraction was good but represented a wide variation, the lowest being 5\%.

Comparison of risk factors showed significant differences (Table 4). There were significantly more Asians who had never smoked, and fasting cholesterol levels were higher in whites. There was no significant difference in triglyceride levels or in the number of diabetics. Whites were heavier and the body surface area (BSA) greater in whites.

TABLE 4. Risk factors

\begin{tabular}{lccc}
\hline & Asian & White & $P$ \\
\hline Smoking (\%) & 68 & 91 & $<0.01$ \\
$\begin{array}{l}\text { Cholesterol } \\
\text { (mmol/litre) }\end{array}$ & $5.9 \pm 1 \cdot 1$ & $6.6 \pm 1.2$ & $<0.01$ \\
Triglyceride & & & \\
$\quad($ mmol/litre) & $2.7 \pm 1.2$ & $2.2 \pm 1.2$ & NS \\
Diabetes (\%) & 9 & 4 & NS \\
Weight (kg) & $70.0 \pm 9.9$ & $76.5 \pm 10.4$ & $<0.01$ \\
BSA (m ( $\left.^{2}\right)$ & $1.8 \pm 0.2$ & $1.9 \pm 0.2$ & $<0.01$ \\
\hline
\end{tabular}

\section{Discussion}

The Asian population in our catchment area come from Pakistan, the Punjab, and a few from Bangledesh, and have been resident in this country for a mean of 13 years. Our impression that the distribution of CAD was different in Asians was incorrect, but significantly more severe CAD in Asians was confirmed. Interestingly, there was also a significant difference in the risk factors between the 2 groups, Asians having fewer smokers, lower cholesterol and weighing less than the whites.

\section{References}

BeEvers, D.G. \& CRuickshank, J.K. (1981) Age, sex, ethnic origin and hospital admission for heart attack and stroke. Postgraduate Medical Journal, 57, 763.

EISENBERG, S., EHRENFEld, M., Friedman, G. \& Friedlander, Y. (1981) Risk factors for coronary artery disease in patients with acute myocardial infarction. Israel Journal of Medical Science, 17, 309.

GILLUM, R.F. (1982) Coronary heart disease in black populations. I. Mortality and morbidity. American Heart Journal, 104, 839.

GilluM, R.F. \& GRANT, C.T. (1982) Coronary heart disease in black populations. II. Risk factors. American Heart Journal, 104, 852. 